\title{
Efeito da aplicação de bissulfato de sódio sobre cama de frangos na sobrevivência de Escherichia coli e coliformes
}

\author{
[Effect of sodium bisulfite application on the bed of broiler \\ on survival of Escherichia coli and coliforms] \\ P.M. Carvalho Neto ${ }^{1,2}$, E.N. Silva ${ }^{2}$, I.A.O. Bassani ${ }^{2}$, O.C. Cunha Neto ${ }^{3}$ \\ ${ }^{1}$ Universidade Federal Rural de Pernambuco \\ Rua Dom Manoel de Medeiros, $\mathrm{s} / \mathrm{n}$ \\ 52171-900 - Recife, PE \\ ${ }^{2}$ Faculdade de Engenharia de Alimentos - UNICAMP \\ ${ }^{3}$ Laboratório de Laticínios - FEAZ - USP
}

\section{RESUMO}

Avaliou-se o efeito do bissulfato de sódio, aplicado sobre a cama de frangos, criados em diferentes densidades, na sobrevivência de Escherichia coli e coliformes, utilizando-se as densidades de 12, 16 e 20 aves $/ \mathrm{m}^{2}$, com a inoculação de uma cepa de $E$. coli. Houve maior desenvolvimento microbiano no $21^{\circ}$ dia de criação, com tendência de redução a partir daí. A eficácia do bissulfato de sódio foi maior nos primeiros dias do experimento.

Palavras-chave: frango de corte, densidade avícola, cama de aviário, bissulfato de sódio

\begin{abstract}
The effect of sodium bisulfate has been evaluated on survival of Escherichia coli and coliforms, when applied on the broiler beds, adopting different densities. It has been adopted densities of 12, 16 and 20 birds $/ \mathrm{m}^{2}$, using inoculations of E. coli strains. The results have shown the highest microbial development on the $21^{\text {st }}$ day of inoculation, with a trend of a microbial reduction afterwards. The sodium bisulfate was efficient during the first days of analyses, reducing its efficacy during the experiment.
\end{abstract}

Keywords: broiler, poultry density, aviaries bed, sodium bisulfate

\section{INTRODUÇÃO}

A criação de frangos em alta densidade populacional é uma prática que visa otimizar os galpões de criação. Passa-se de uma produção de, aproximadamente, $28 \mathrm{~kg}$ de ave-viva por metro quadrado de piso nas criações convencionais para, até, $50 \mathrm{~kg} / \mathrm{m}^{2}$, nas criações em alta densidade.

Essa alteração na prática de manejo interfere na ambiência e no conforto animal. Também, há maior acúmulo de dejetos na cama - geralmente constituída de maravalha de madeira - levando à maior produção de gases no ambiente, por ação microbiana sobre o material fecal. Essas condições aumentam a predisposição às doenças, principalmente as respiratórias (Luchesi, 1998), e reduzem a produtividade animal (Nääs et al., 2001).

Galpões com melhor estrutura física e equipamentos que permitem melhor ventilação são processos auxiliares na redução dos efeitos negativos da criação em alta densidade. 
A população microbiana na cama usada de frangos varia consideravelmente, inclusive a de patógenos, mas não a de Escherichia coli, conforme constataram Terzich et al. (2000), ao analisarem a prevalência de microrganismos na cama de frango. E. coli é o principal agente complicador dos problemas respiratórias em frango de corte, que são exacerbados na presença do gás amônia (Silva, 1999).

A redução dos níveis da população microbiana da cama conduz a uma menor produção de amônia (Cherry et al., 1998). A incorporação do produto químico bissulfato de sódio em pó, tem sido proposta como meio de diminuir a contaminação microbiana da cama de frangos e, conseqüentemente, a emanação de gases. Assim, haveria redução dos problemas respiratórios e melhora no rendimento de frangos criados sobre cama tratada (Terzich et al., 1998; Pope e Cherry, 2000).

O objetivo deste trabalho foi avaliar a ação do bissulfato de sódio, aplicado sobre a cama de frangos, na sobrevivência de $E$. coli e coliformes.

\section{MATERIAL E MÉTODOS}

Utilizou-se um galpão limpo e desinfetado, dividido em duas partes, com dimensões padronizadas de $4,25 \mathrm{~m}^{2}$ cada uma. Utilizaram-se 27 boxes equipados com campânula elétrica, comedouros e bebedouros de acordo com a fase produtiva da ave e a densidade de locação. Pintos de corte da linhagem Ross, de ambos os sexos, com um dia de idade, já vacinados contra gumboro e Marek no incubatório, foram alojados em três dias consecutivos, submetidos ao arraçoamento à vontade e pesados semanalmente até o abate, com 40 dias.

O bissulfato de sódio, principal componente químico do produto comercial ${ }^{1}\left(\mathrm{PLT}^{\circledR}\right)$, granuloso e seco, foi desenvolvido para o controle da amônia produzida na cama, decorrente da redução do pH. A ação do bissulfato de sódio foi avaliada, quanto à sua capacidade em reduzir a população de uma cepa de E. coli mutante, previamente inoculada à cama (tipo maravalha) antes do alojamento dos pintos até atingirem os 28 dias de idade. A contagem dos coliformes iniciou-se com um dia de idade dos pintos até os 35 dias. A cepa mutante era resistente ao ácido nalidíxico $(E$. coli $\mathrm{Nal}^{\mathrm{R}}$ ) para facilitar sua recuperação e identificação.

Nos boxes, a distribuição dos tratamentos, em triplicata, foi feita de maneira aleatória, separandose os grupos com os diferentes tratamentos por um boxe vazio. O delineamento estatístico adotado foi inteiramente ao acaso, e os tratamentos foram distribuídos em arranjo fatorial $3 \times 3$ ( três densidades de criação: 12,16 e 20 aves $/ \mathrm{m}^{2}$ x três tratamentos da cama de frango: E. coli $\mathrm{Nal}^{\mathrm{R}}$ não tratada, E. coli $\mathrm{Nal}^{\mathrm{R}}$ tratada e testemunha sem $E$. coli).

As amostras de cama foram coletadas semanalmente, com intervalo de um dia entre as replicações de criação. Para as análises microbiológicas, foram pesadas $10 \mathrm{~g}$ da amostra da cama adicionada em $90 \mathrm{ml}$ de água peptonada e homogeneizada. Alíquotas de $0,1 \mathrm{ml}$ das diluições decimais foram espalhadas na superfície das placas de Petri contendo ágar McConkey adicionado de $100 \mu \mathrm{g}$ de ácido nalidíxico por mililitro do meio. Para as análises de coliformes, utilizou-se o meio ágar vermelho violeta bile 4-metilumbeliferil-ß-Dglicuronídeo-VRB-MUG, com a identificação dos coliformes fecais mediante técnica de fluorescência utilizando-se fonte ultravioleta.

Os dados obtidos foram submetidos à análise de variância, e as médias comparadas pelos testes $\mathrm{t}$ e Tukey $(\mathrm{P}<0,05)$, quando necessário. Foram utilizados os aplicativos Statistica, SAS (User's..., 1995) e Excel para análise dos dados.

\section{RESULTADOS E DISCUSSÃO}

Não houve efeito da densidade de criação sobre a contagem de $E$. coli $\mathrm{Nal}^{\mathrm{R}}$ das camas contaminadas e tratadas com bissulfato de sódio (Tab. 1). Nas camas contaminadas, houve diferença $(\mathrm{P} \leq 0,05)$ entre a contagem bacteriana das camas tratadas e não tratadas. Apesar de as médias terem valores relativamente próximos, ocorreu ação do bissulfato de sódio na redução do microrganismo indicador. Estes resultados confirmam os encontrados por Pope e Cherry (2000), cujas contagens de E. coli nas semanas um e dois, nas camas tratadas com bissulfato de sódio foram mais baixas em relação às dos galpões do grupo-controle.

${ }^{1}$ Poultry Litter Treatment $\left(\right.$ PLT $\left.^{\circledR}\right)$ - Jones Hamilton C., Walbridge, Ohio, EUA. 
Tabela 1. Contagem de E. coli $\mathrm{Nal}^{\mathrm{R}}$ em camas de frangos tratadas ou não com bissulfato de sódio $\left(2 \mathrm{NaHSO}_{4}\right)$ durante o período de 28 dias

\begin{tabular}{lc}
\hline Tratamento & E. coli $\mathrm{Nal}^{\mathrm{R}}$ \\
\cline { 2 - 2 }$\left(\mathrm{UFC}_{\log 10} / \mathrm{g}\right)^{2} \pm \mathrm{DP}$ \\
\hline E. coli $\mathrm{Nal}^{\mathrm{R}}$ não tratada & $7,6 \mathrm{a} \pm 1,36$ \\
E. coli $\mathrm{Nal}^{\mathrm{R}}$ tratada & $5,4 \mathrm{~b} \pm 2,18$
\end{tabular}

Médias na coluna seguidas letras distintas diferem entre si pelo teste $\mathrm{t}(\mathrm{P}<0,01)$.

E. coli $\mathrm{Nal}^{\mathrm{R}}=$ cepa de Escherichia coli resistente a $100 \mu \mathrm{g}$ de ácido nalidíxico; $\mathrm{UFC}_{\log 10} / \mathrm{g}=$ unidade formadora de colônia, $\log _{10} / \mathrm{g} / \mathrm{amostra} ; \mathrm{DP}=$ desvio padrão; 27 amostras de camas de frangos para cada tratamento.
$\mathrm{Na}$ Tab. 2 estão os valores médios da contagem de $E$. coli $\mathrm{Nal}^{\mathrm{R}}$ nas camas tratadas e não tratadas com bissulfato de sódio, de acordo com a idade das aves e a densidade de criação. Nas tratadas, o aumento da densidade, em geral, resultou em elevação das médias na contagem aos 28 dias, em comparação com as médias dos dias zero e um. Nas camas com $E$. coli $\mathrm{Nal}^{\mathrm{R}}$ não tratadas, a média da contagem com 28 dias foi inferior à dos dias iniciais, o que pode ser atribuído à interferência do tipo de cama e do seu manejo quanto à umidade, temperatura e pH na emissão de amônia (Miragliotta, 2000; Eriksson de Rezende et al., 2001).

Tabela 2. Contagem de E. coli $\mathrm{Nal}^{\mathrm{R}}$ em cama de frangos tratadas ou não com bissulfato de sódio $\left(2 \mathrm{NaHSO}_{4}\right)$, de acordo com a idade e densidades de criação

\begin{tabular}{|c|c|c|c|}
\hline \multirow[b]{2}{*}{ Tratamento } & \multirow[b]{2}{*}{ Densidade } & \multirow{2}{*}{$\begin{array}{l}\text { Idade } \\
\text { (dias) }\end{array}$} & \multirow{2}{*}{$\frac{\text { E. coli } \mathrm{Nal}^{\mathrm{R}}}{\left(\mathrm{UFC}_{\log 10} / \mathrm{g}\right) \pm \mathrm{DP}}$} \\
\hline & & & \\
\hline E. coli $\mathrm{Nal}^{\mathrm{R}}$ não tratada & 12 & 0 & $8,2 \pm 0,95$ \\
\hline E. coli $\mathrm{Nal}^{\mathrm{R}}$ não tratada & 12 & 1 & $8,6 \pm 1,94$ \\
\hline E. coli $\mathrm{Nal}^{\mathrm{R}}$ não tratada & 12 & 28 & $7,7 \pm 1,11$ \\
\hline E. coli $\mathrm{Nal}^{\mathrm{R}}$ não tratada & 16 & 0 & $6,3 \pm 0,34$ \\
\hline E. coli $\mathrm{Nal}^{\mathrm{R}}$ não tratada & 16 & 1 & $7,6 \pm 0,67$ \\
\hline E. coli $\mathrm{Nal}^{\mathrm{R}}$ não tratada & 16 & 28 & $7,3 \pm 1,20$ \\
\hline E. coli $\mathrm{Nal}^{\mathrm{R}}$ não tratada & 20 & 0 & $7,1 \pm 2,04$ \\
\hline E. coli $\mathrm{Nal}^{\mathrm{R}}$ não tratada & 20 & 1 & $8,7 \pm 1,49$ \\
\hline E. coli $\mathrm{Nal}^{\mathrm{R}}$ não tratada & 20 & 28 & $6,3 \pm 0,18$ \\
\hline E. coli $\mathrm{Nal}^{\mathrm{R}}$ tratada & 12 & 0 & $4,5 \pm 0,78$ \\
\hline E. coli $\mathrm{Nal}^{\mathrm{R}}$ tratada & 12 & 1 & $3,1 \pm 1,14$ \\
\hline E. coli $\mathrm{Nal}^{\mathrm{R}}$ tratada & 12 & 28 & $6,8 \pm 1,16$ \\
\hline E. coli $\mathrm{Nal}^{\mathrm{R}}$ tratada & 16 & 0 & $4,9 \pm 3,29$ \\
\hline E. coli $\mathrm{Nal}^{\mathrm{R}}$ tratada & 16 & 1 & $4,9 \pm 4,02$ \\
\hline E. coli $\mathrm{Nal}^{\mathrm{R}}$ tratada & 16 & 28 & $6,3 \pm 0,66$ \\
\hline E. coli $\mathrm{Nal}^{\mathrm{R}}$ tratada & 20 & 0 & $4,7 \pm 2,39$ \\
\hline E. coli $\mathrm{Nal}^{\mathrm{R}}$ tratada & 20 & 1 & $7,0 \pm 2,19$ \\
\hline E. coli $\mathrm{Nal}^{\mathrm{R}}$ tratada & 20 & 28 & $6,3 \pm 1,06$ \\
\hline
\end{tabular}

Dias: tempo após a inoculação de $E$. coli $\mathrm{Nal}^{\mathrm{R}}: 0$ dia=24h antes da chegada dos pintos; 1 dia=24h após a chegada dos pintos; 28 dias=dia da última inoculação; $\mathrm{UFC}_{\log 10} / \mathrm{g}=$ unidade formadora de colônia, $\log _{10} / \mathrm{g} / \mathrm{amostra} ; \mathrm{DP}=\mathrm{desvio}-$ padrão; três amostras por tratamento/densidade/idade.

$\mathrm{Na}$ Tab. 3 estão as contagens de E. coli $\mathrm{Nal}^{\mathrm{R}}$ e coliformes nas camas de frangos. Os resultados da contagem na cama tratada com bissulfato de sódio foram mais baixos que o da cama não tratada e da cama testemunha, o que está de acordo com os resultados obtidos por Pope e Cherry (2000).

As contagens microbiológicas de E. coli $\mathrm{Nal}^{\mathrm{R}} \mathrm{e}$ coliformes oriundas das camas contaminadas por $E$. coli $\mathrm{Nal}^{\mathrm{R}}$, tratadas ou não com bissulfato de sódio, e 
da cama testemunha, nos diferentes dias de determinação das análises experimentais, são

apresentadas na Tab. 4.

Tabela 3. Contagem microbiana de E. coli $\mathrm{Nal}^{\mathrm{R}}$ e coliformes em camas de frangos experimentalmente contaminadas por $E$. coli $\mathrm{Nal}^{\mathrm{R}}$, tratadas ou não com bissulfato de sódio $\left(2 \mathrm{NaHSO}_{4}\right)$, e em cama testemunha

\begin{tabular}{lccc}
\hline \multirow{2}{*}{ Tratamento } & E. coli $\mathrm{Nal}^{\mathrm{R}}$ & Coliformes & $\mathrm{n}$ \\
\cline { 2 - 3 } & $\left(\mathrm{UFC}_{\log 10} / \mathrm{g}\right) \pm \mathrm{DP}$ & $\left(\mathrm{UFC}_{\log 10} / \mathrm{g}\right) \pm \mathrm{DP}$ & 53 \\
\hline E. coli $\mathrm{Nal}^{\mathrm{R}}$ não tratada & $7,8 \mathrm{a} \pm 1,82$ & $7,9 \mathrm{a} \pm 1,74$ & 50 \\
E.coli $\mathrm{Nal}^{\mathrm{R}}$ tratada & $6,3 \mathrm{~b} \pm 2,50$ & $6,8 \mathrm{~b} \pm 2,36$ & 51 \\
Testemunha & $7,8 \mathrm{a} \pm 1,64$ & $7,9 \mathrm{a} \pm 1,66$ & 51 \\
\hline
\end{tabular}

Médias na coluna seguidas por letras distintas diferem entre si pelo teste Tukey ( $\mathrm{P} \leq 0,05)$.

E. coli $\mathrm{Nal}^{\mathrm{R}}=$ cepa de $E$. coli resistente a $100 \mu \mathrm{g}$ de ácido nalidíxico; $\mathrm{UFC}_{\log 10} / \mathrm{g}=$ unidade formadora de colônia, $\log _{10} / \mathrm{g} /$ amostra; $\mathrm{DP}=$ desvio-padrão; testemunha= controle sem tratamento.

Tabela 4. Contagens (UFC ${ }_{\log 10} / \mathrm{g}$ ) microbianas em camas de frangos experimentalmente contaminadas com E. coli, tratadas ou não com bissulfato de sódio $\left(2 \mathrm{NaHSO}_{4}\right)$, e em cama testemunha

\begin{tabular}{lcccc}
\hline Tratamento & Tempo (dias) & E. coli $\mathrm{Nal}^{\mathrm{R}}$ & Coliformes & $\mathrm{N}$ \\
\hline E. coli $\mathrm{Nal}^{\mathrm{R}}$ não tratada & 0 & $8,7 \mathrm{a}$ & $8,7 \mathrm{a}$ & 9 \\
E. coli $\mathrm{Nal}^{\mathrm{R}}$ não tratada & 7 & $7,1 \mathrm{a}$ & $7,1 \mathrm{a}$ & 9 \\
E. coli $\mathrm{Nal}^{\mathrm{R}}$ não tratada & 14 & $7,5 \mathrm{a}$ & $7,7 \mathrm{a}$ & 9 \\
E. coli $\mathrm{Nal}^{\mathrm{R}}$ não tratada & 21 & $8,7 \mathrm{a}$ & $8,9 \mathrm{a}$ & 9 \\
E. coli $\mathrm{Nal}^{\mathrm{R}}$ não tratada & 28 & $7,8 \mathrm{a}$ & $7,8 \mathrm{a}$ & 9 \\
E. coli $\mathrm{Nal}^{\mathrm{R}}$ não tratada & 35 & $6,9 \mathrm{a}$ & $7,3 \mathrm{a}$ & 8 \\
E. coli $\mathrm{Nal}^{\mathrm{R}}$ tratada & 0 & $2,0 \mathrm{~b}$ & $2,0 \mathrm{~b}$ & 5 \\
E. coli $\mathrm{Nal}^{\mathrm{R}}$ tratada & 7 & $6,5 \mathrm{ab}$ & $6,5 \mathrm{ab}$ & 9 \\
E. coli $\mathrm{Nal}^{\mathrm{R}}$ tratada & 14 & $7,3 \mathrm{ab}$ & $7,5 \mathrm{a}$ & 9 \\
E. coli $\mathrm{Nal}^{\mathrm{R}}$ tratada & 21 & $8,8 \mathrm{a}$ & $9,1 \mathrm{a}$ & 9 \\
E. coli $\mathrm{Nal}^{\mathrm{R}}$ tratada & 28 & $5,8 \mathrm{ab}$ & $7,1 \mathrm{ab}$ & 9 \\
E. coli $\mathrm{Nal}^{\mathrm{R}}$ tratada & 35 & $5,6 \mathrm{ab}$ & $6,5 \mathrm{ab}$ & 9 \\
Testemunha $_{\text {Testemunha }}$ & 0 & $8,0 \mathrm{a}$ & $7,9 \mathrm{a}$ & 7 \\
Testemunha $_{\text {Testemunha }}$ & 7 & $7,5 \mathrm{a}$ & $7,4 \mathrm{a}$ & 8 \\
Testemunha $_{\text {Testemunha }}$ & 14 & $8,2 \mathrm{a}$ & $8,3 \mathrm{a}$ & 9 \\
\hline Para & 21 & $8,4 \mathrm{a}$ & $8,7 \mathrm{a}$ & 9 \\
\hline
\end{tabular}

Para o mesmo tratamento, na coluna, médias seguidas por letras distintas diferem entre si pelo teste Tukey $(\mathrm{P} \leq 0,05)$. E. coli $\mathrm{Nal}^{\mathrm{R}}=$ cepa de $E$. coli resistente a $100 \mu \mathrm{g}$ de ácido nalidíxico; $\mathrm{UFC}_{\log 10} / \mathrm{g}=$ unidade formadora de colônia, $\log _{10} / \mathrm{g} / \mathrm{amostra}$; testemunha=controle sem tratamento; $\mathrm{n}=$ número de amostras de camas de frangos em três replicações.

No dia inicial (zero), observou-se diferença entre as contagens microbiológicas das camas de frangos contaminadas por E. coli $\mathrm{Nal}^{\mathrm{R}}$ não tratada e testemunha e a contagem da cama tratada com bissulfato de sódio, confirmando a atividade redutora do bissulfato de sódio sobre esses microrganismos. Estes resultados diferem dos de Pope e Cherry (2000), que não encontraram diferenças nos valores das contagens entre as camas tratadas com bissulfato de sódio e as camas do grupo-controle.

Nas camas com E. coli $\mathrm{Nal}^{\mathrm{R}}$ tratadas, observouse diferença significativa entre a contagem do dia zero e a do $21^{\circ}$ dia, mas isso não ocorreu nas 
duas outras camas. O comportamento para os coliformes foi semelhante. Apenas acrescente-se a diferença observada na cama tratada também no dia 14 em relação ao dia zero.

As contagens aos 28 e 35 dias foram mais baixas que as do dia 21 , o que pode ser atribuído à interferência do tipo de cama e do seu manejo quanto à umidade, temperatura, $\mathrm{pH}$, ventilação e produção de amônia (Atkinson et al., 1996; Miragliota, 2000; Tiquia et al., 2002; Das et al., 2002).

\section{CONCLUSÕES}

Conclui-se que houve eficácia do bissulfato de sódio nas camas tratadas nos primeiros dias de alojamento e que o maior desenvolvimento microbiano ocorreu no $21^{\circ}$ dia de criação.

\section{AGRADECIMENTOS}

Os autores agradecem à USP - Campus de Pirassununga pela disponibilização das instalações e equipamentos na realização do experimento.

\section{REFERÊNCIAS BIBLIOGRÁFICAS}

ATKINSON, C.F.; JONES, D.D.; GAUTHIER, J.J. biodegradability and microbial activities during composting of poultry litter. Poult. Sci., v.75, p.608$617,1996$.

CHERRY, T.E.; BAXTER, J.A.; TERZICH, M. The effects of poultry litter treatment on poultry house environment and litter quality for broiler chickens. In: WESTERN POULTRY DISEASE CONFERENCE, 47., 1998, Davis. Proceedings... Davis: University of California, 1998. p.77-78.

DAS, K.C.; MINKARA, M.Y.; MELEAR, N.D. et al. Effect of poultry litter amendment on hatchery waste composting. J. Appl. Poult. Res., v.11, p.282-290, 2002.
ERIKSSON DE REZENDE, C.L.; MALLINSON, E.T.; TABLANTE, N.L. et al. Effect of dry litter and airflow in reducing salmonella and Escherichia coli populations in the broiler production environment. $J$. Appl. Poult. Res., v.10, p.245-251, 20001.

LUCHESI, J.B. Custo-beneficio da criação de frangos de corte em alta densidade no inverno e no verão. In: CONFERÊNCIA APINCO'98 DE CIÊNCIA E TECNOLOGIA AVÍCOLAS, 1998, Campinas. Anais... Campinas-SP: Facta, 1998. p.241-248.

MIRAGLIOTTA, M.Y. Avaliação dos niveis de amônia em dois sistemas de produção de frangos de corte com ventilação e densidade diferenciados. 2000. 122f. Dissertação (Mestrado em Engenharia Agrícola) - Faculdade de Engenharia Agrícola, Universidade Estadual de Campinas, Campinas, SP.

NÄÄS, I.A.; BARACHO, M.S.; MIRAGLIOTTA, M.Y. Produção avícola e meio ambiente. In: SIMPÓSIO SOBRE PRODUÇÃO ALTERNATIVA DE FRANGOS, 2001, Campinas. Anais ... Campinas: Facta, 2001. v.2, p.273-283.

POPE, M.J.; CHERRY, T.E. An evaluation of the presence of pathogens on broilers raised on poultry litter treatment ${ }^{\circledR}$ - Treated litter. Poult. Sci., v.79, p.1351-1355, 2000 .

SILVA, E.N. Salmonelose aviária e suas implicações no contexto da saúde pública. In: CONGRESSO PERNAMBUCANO DE MEDICINA VETERINÁRIA, 1999. Recife. Anais... Recife: SPEMVE, 1999. p.25-34.

TERZICH, M.; QUARLES, C.; GOODWIN, M.A. et al. Effect of poultry treatment (PLT) on death due to ascites in broilers. Avian Dis., v.42, p.385-387, 1998.

TERZICH, M.; POPE, M.J.; CHERRY, T.E. et al. Survey of pathogens in poultry litter in the United States. J. Appl. Poult. Res., v.9, p.287-291, 2000.

THIQUIA, S.M.; WAN, J.H.C., TAM, N.F.Y. Microbial population dynamics and enzyme activities during composting. Comp. Sci. Utiliz., v.10, p.150$161,2002$.

USER'S guide: statistics. Cary, NC: SAS Institute, 1995. 